\title{
Apical instrumentation in endodontic therapy
}

\author{
Kurniasri Darliana, Endang Sukartini
}

Department of Conservative Dentistry Faculty of Dentistry Universitas Padjadjaran

\begin{abstract}
Cleaning and shaping of the root canal as the foundation for successful endodontic therapy. Cleaning of the root canal as the removal of all the contents of the root canal systems before and during shaping. Mechanical cleaning as the most important part of the root canal therapy. Instrumentation of the apical region has long been considered to be an essential component in the cleaning and shaping process. The apical area as the critical zone for instrumentation. The apical portion of the root canal system can retain microorganisms that could potentially cause periradicular inflammation. The nickel-titanium rotary instrumentation system to facilitate the cleaning and shaping process. Larger instrumentation sizes not only allow proper irrigation but also significantly decrease remaining bacteria in the canal system. How the larger apical sizes preparation must be achieve to clinical success. This paper will describe about the major factors impacting the selection of final apical size, the factors are the anatomy of the apical constriction, root canal diameter, apical instrumentation, and bacteria in dentin tubuli.
\end{abstract}

Key words: Endodontic treatment, apical preparation, apical constriction.

\section{INTRODUCTION}

The main purpose of root canal treatment is to minimize the number of microorganisms and pathologic debris in root canal system to prevent or cure periodontitis at the apical site. Debridement is a process to remove all root canal contents before and when root canal formation takes place. Grossman et al. ${ }^{1}$ said that mechanical cleaning was an important measure in root canal treatment. Schlider ${ }^{2}$ also considered that root canal cleaning and formation were the basis of endodontic treatment success.

Applying instrumentation in the apical part of the root canal is considered as an important component in root canal cleaning and formation process. Simon ${ }^{3}$ said that the apical site was a critical zone when applying instrumentation. Rotary instrument made of nickel titanium was used for root canal cleaning and formation. The device became popular because it was easy to use. Applying nickel titanium would reduce the number of instruments used for root canal cleaning and formation. However, Spangberg ${ }^{4}$ asserted that the reduced number of instruments used and limiting apical preparation only for small numbers would not allow a proper root canal cleaning to be performed.

Howbigisthefinalsizeof rootcanalpreparation at apical should be in order to make the endodontic treatment successful? It is very much affected by several factors, i.e. apical constriction anatomy, root canal diameter, apical instrumentation and microorganisms within dentin tubule. 


\section{APICAL CONSTRICTION}

Mechanical instrumentation and irrigation are an endodontic treatment principles and an important component that support the endodontic treatment success. Instrumentation in the apical site is considered as an important component of root canal cleaning and formation. Simon ${ }^{3}$ stated that the apical site was a critical zone in instrumentation, i.e. several millimeters near the apical foramen.

\section{Apical constriction location, shape and diameter}

Apical constriction, in this case the cementoenamel junction is a place that is agreed as the end of root canal instrumentation and obturation. Cementoenamel junction is the narrowest site in the root canal, and also the place when the pulp is ended and the initial of the periodontal tissue. In young apex, the apical is located $0.5 \mathrm{~mm}$ from the cementum surface, and in mature apex, $0.75 \mathrm{~mm}$.

The apical constriction that has been studied by Mizutani et al. ${ }^{5}$ showed a cementoenamel junction irregularity. The shape could be oval, long-oval, band or round, but tended to be oval. Clinically, it shows that the best diameter of root canal should consider whether the instrumentation that would be applied on this site would be able to remove the debridement from the root canal.

The horizontal measure from this apical constriction varies in each root canal. A dentist should consider the patient's age when planning endodontic treatment strategy, recalling that the cementum will experience on-going deposition

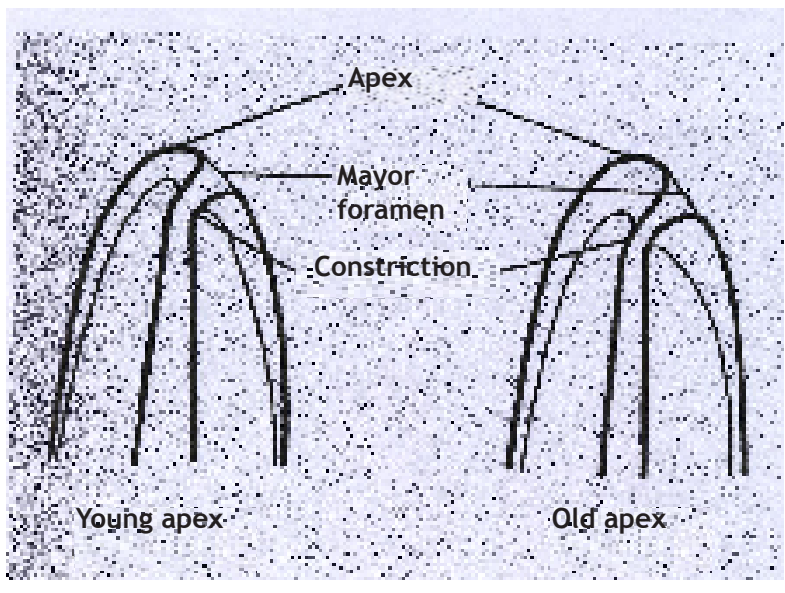

Figure 1. Apical constriction. for a life time. Ponce and Fernandez ${ }^{6}$ studied cementoenamel junction on 18 anterior teeth. They stated that the apical constriction diameter is between $29-35 \mathrm{~mm}$.

\section{Root canal diameter}

Endodontic treatment can be divided into three phases, i.e. cleaning and formation, disinfection, and root canal obturation. The root canal cleaning and formation consist of pulp chamber access preparation and root canal preparation with root canal irrigation. ${ }^{1}$

The general purposes of root canal preparation are cleaning, shaping and smoothing the root canal. Root canal system must be cleaned from necrotic tissue, vital pulp tissue, pulp tissue residuals, soft and infected dentin and the number of toxins and microorganisms must be reduced. ${ }^{1}$

\section{Ideal root canal preparation shape}

Numerous ways have been applied for years to find out the ideal root canal mechanical preparation based on knowledge about root canal obturation. Instrumentation process for ideal root canal preparation should have a big diameter in coronal orifice and is narrowed to the small diameter apical constriction. Buchanan ${ }^{7}$ suggested avoiding an excessive enlargement on apical site (by making) minimun root canal narrowing. Walton and Torabinejad $^{8}$, said that root canal should be shaped into continuous cone shape from apex to coronal part.

\section{Root canal enlargement purpose}

Root canal needs to be enlarged sufficiently to eliminate debris and to apply a proper irrigation until one third of apical in the root canal. Walton and Torabinejad $^{8}$ said that the root canal must be shaped so it could receive the medicine optimally, in order to facilitate the three dimensions filling hermetically on the entire root canal. Ram ${ }^{9}$ suggested that the root canal weeded to be enlarged to number 40 file, so the maximal irrigation was able to contact apical debris. If smaller file is used, (the debris) will not be disposed out by irrigation. Orstavik and Haapasalo ${ }^{10}$ stated that the instrumentation with number 45 file is appropriate for reducing bacteria growth by tenfold. Bigger file application was needed so the irrigation liquid can reach the 
apex to reduce the bacteria in the root canal.

\section{Microorganism in dentin tubule}

Root canal instrumentation and irrigation are not always able to eliminate all microorganisms. Bacteria can penetrate into the dentin tubule and stick firmly, so they are hard to be eliminated and terminated.

Akpata and Blechaman ${ }^{11}$ demonstrated that if the number of bacteria inside the root canal increases the penetration into dentin tubule also increased. Orstavik and Haapasalo ${ }^{10}$ found that Enterococcus faecalis and Streptococcus sanguis could invade dentin tubule from $300 \mu \mathrm{m}$ to $400 \mu \mathrm{m}$ within two until three weeks. Peter ${ }^{12}$ reported that Enterococcus faecalis penetrates into the dentin tubule deeper than Actinomyecs Israelii and will penetrate better if there is no smear layer.

Root canal preparation would leave a smear layer that was amorph from dentin and other debris, 1 to $4 \mu \mathrm{m}$ on the root canal wall and enter the dentin tubule as far as $40 \mu \mathrm{m}$. The smear layer would affect dentin permeability and inhibit bacterial colonization.

\section{Microorganism location in dentin tubule}

Bacteria that are left in the dentin tubule of the root canal can cause infection during root canal treatment resulting in endodontic treatment failure.

Love $^{13}$ said that the bacterial invasion and the penetration into dentin tubule take place in the cervical site and the mid root up to 200 $\mu \mathrm{m}$ meanwhile in the apical site it is $60 \mu \mathrm{m}$. Matsuo ${ }^{14}$ suggested that the dentin tubule has up to $70 \%$ bacteria in it and some of them reach the cementum. Since long time ago, Intracanal medication has been suggested for infection treatment and to eliminate microorganisms in dentin tubule.

Weiger ${ }^{15}$ found that in certain conditions, Streptococcus sanguis and Enterococcus faecalis are still found, although they have already been treated with calcium hydroxide.

\section{Apical instrumentation}

The root canal apex can store microorganisms that are potential for causing periradicular inflammation. Nair ${ }^{16}$ found that, although a long term therapy has been applied, apical microflora still played an important role in causing endodontic treatment failure. Therefore, the action to eliminate infected dentin when applying root canal instrumentation is very important.

\section{Standard for adequate apical preparation}

Instructions or standards for apical preparation is supported by Weine. ${ }^{17}$ Weine ${ }^{17}$ suggested to enlarge the apical site of the root canal up to three times bigger than the first file used until sufficient work-length had been achieved. However, other writer concluded that it was still debatable, whether using file three times bigger than the first file would eliminate dentin around the root canal adequately. Buchanan ${ }^{7}$ suggested that minimizing certain apical preparation, e.g. by only using number 20 or number 25 file only.

Enlarging root canal size cauld cause apical transformation and zips, whereas minimal apical preparation can prevent iatrogenic instrumentation. Original (former) size, anatomy shape, and easy access of the canal determine the biggest file size that should be used in apical preparation. If apical preparation is enlarged to number 30 file, and the next size will not reach work-length then the preparation of one third apical is sufficient and it will finish up to number 30. Apical site cleaning engages the biggest last file that is rotated according to the work-length, and followed by root canal irrigation and drainage. Canal cleaning will effectively eliminates residual debris on the wall of one third root canal area.

Sequeira ${ }^{18}$ illustrated that although there was bacterial reduction during apical enlargement, the perfect debridement was impossible to be obtained. Basically, all studies provide strong consensus that big apical preparation will result in better residue bacterial and dentin debris reduction than the small apical preparation.

\footnotetext{
Apical constriction role in endodontic treatment

Walton and Torabinejad $^{8}$ suggested that apical constriction has several roles, i.e.: To prevent the instruments, materials, and chemicals from passing the root canal; To establish a barrier, so it can restraint the gutaperca during condensation.

Ricucci $^{19}$ suggested applying the instrumentation up to the apical constriction
} 
since instrumentation to an area farther than this are would cause injury. In an endodontic treatment, waiting for wound recovery would lead to negative effects. If the medication and materials exceed the apical constriction, it would result in inflammation. Instrumentation and obturation to the apical constriction will provide a good prognosis. However, it was not an easy task to determine the apical constriction location.

\section{CONCLUSION}

The main factors that affect the final apical size selection are apical constriction anatomy, apical preparation, root canal diameter, and microorganisms in dentin tubule. The apical part of the root canal should be enlarged into an appropriate size to perform perfect debridement and to manipulate and control filler and instruments in an appropriate manner. Better bacterial reduction that is followed by an effective irrigation will happen if the apical site of the root canal is enlarged to a size that is three times bigger than the first file size that enter until sufficient work-length is achieved.

\section{REFERENCES}

1. Grossman LI, Oliet S, Del Rio CE. Endodontic practice. $11^{\text {th }}$ ed. Philadelphia: Lea \& Febiger; 1988.

2. Schlider $\mathrm{H}$. Cleaning and shaping the root canal. Dent Clin North Am 1974;18:269.

3. Simon J. The apex: How critical is it? Gen Dentistry 1994;42:330-4.

4. Spangberg L. The wonderful word of rotary root canal preparation. J Oral Surg Oral Med. Oral Path Oral Radio Endodont 2001;92:479.

5. Mizutani T, Ohno N. Anatomical study of the root apex in the maxillary anterior teeth. J Endodont 1996;22:290-3.

6. Ponce E. Fernandez J. The cementodentino canal junction the apical foramen and the apical constriction: Evaluation by optical microscopy. J Endodont 2003;29:214-8.

7. Seidler B. Root canal filling: An evaluation and method. J Am Dent Assoc 1956;53:567-76

8. Buchanan LS. The standardized taper root canal preparation: part 1. Concepts for variably tapered shaping instruments. Int Endodon J 2000;33:516-29.

9. Walton R, Torabinejad $M$. Principles and practice of endodontics. $2^{\text {nd }}$ ed. Philadelphia: W.B. Saunders Co.; 1996.

10. Ram Z. Effectiveness of root canal irrigation. Oral Surg 1977;44:306-12.

11. Orstavik, Haapasalo. Desinfection by endodontic irrigans and dressing of experimentally infected if dentinal tubules. Endodont Dent Traumatol 1990;60:142-9.

12. Blechaman A. Bacterial invasion of pulpal dentin wall in vitro. J Dent Rest 1982;61:4358.

13. Peters I, Wsselink P, Moorer W. Penetration of bacteria in bovine root dentine. Int Endodon $\mathrm{J}$ 2000;33:28-36.

14. Love RM. Regional variation in root dentinal tubule infection by Streptococcus gordonii. J Endodont 1996;22:290-3.

15. Matsuo T, Shirakami T, Ozaki K, Nakanishi T, Yumoto $\mathrm{H}$, Ebisu S. An immunohistological study of the localization of bacteria invading root pulpa walls with teeth with periapical lesions. J Endodont 29:194-200.

16. Weiger R, De Lucena J, Decaer H, Lost C. Vitality status of microorganisms in infected human root dentine. Int Endodon J 2002;35:166-71.

17. Nair PN, Sjogren U, Krey G, Khanberg KE. Intraradicular bacteria and fungi in root filled, asymptomatic human teeth with therapy resistant periapical lesions. J Endodont 1990;34:250-9.

18. Weine F. Endodontic therapy. $5^{\text {th }}$ ed. St. Louis: C.V Mosby Inc.; 1982:209-22.

19. Yared GM, Dagher FE. Influence of enlargement on bacterial infection during treatment of apical periodontitis. J Endodont 1994;20:5357.

20. Siqueira J, Araujo M. Histological evaluation of the effectiveness of five instrumentation techniques for cleaning the apical third of root canals. J Endodon 1997;23:119-25.

21. Ricucci D. apical limit of root canal instrumentation and obturation. Part 1: Literature review. Int Endodont 1998;31:38493. 